\title{
CUERPOS, LENGUAJES, MIRADAS: TRES NARRADORAS BRITÁNICAS CONTEMPORÁNEAS
}

\author{
Carolina Sánchez-Palencia Carazo \\ Universidad de Sevilla
}

\begin{abstract}
During the last three decades critical attention has turned to the body as a site of negotiation and conflict. No longer considered as the stable and coherent locus of identity, our anatomy (and the ways we relate to it) is now being explored within the cultural paradigms of feminism and poststructuralism that simply question its fixed givenness. Angela Carter, Fay Weldon and Jeanette Winterson are among the contemporary female writers who have addressed the body from non-essentialist perspectives by trying to disentangle it from its associated patriarchal meanings.
\end{abstract}

"En el cuerpo, objeto o sujeto, individual o social, inmóvil o desinhibido, se esculpen las presiones de la convención, las etiquetas represivas del canon, las nociones más marginadoras de normalidad. Pero también las metáforas más rebeldes, plurales y renovadoras de una conciencia que revisa la historia con mayúsculas y minúsculas" (Coordinadora del Encuentro de Mujeres de Iberoamérica en las Artes Escénicas. Festival Iberoamericano de Teatro. Cádiz, 1999).

Con una reflexión tan contundente como perturbadora se despedía aquel encuentro de escritoras teatrales iberoamericanas, que en esa ocasión versaba sobre la representación del cuerpo en la escena. Aunque el área de influencia de aquel manifiesto pretendía ser bien diferente a la de este artículo -la presencia del cuerpo femenino en la obra de Angela Carter, Fay Weldon y Jeanette Winterson- la centralidad de esa controversia respecto a la posibilidad de re-significar el cuerpo (concretamente el cuerpo femenino) en la cultura contemporánea, ha trascendido fronteras literarias y geográficas para servirnos aquí y ahora de punto de partida; porque es precisamente esa cualidad problemática la que subyace al actual debate sobre las políticas del cuerpo, y es en ese espacio de conflicto y de turbulencias donde el presente trabajo quiere ubicarse.

Si efectivamente el cuerpo femenino ha sido -y sigue siendo- un instrumento de represión, ¿es posible plantear una política corporal alternativa? ¿pueden las mujeres reivindicar y recuperar su propio cuerpo para la cultura, y convertirlo en una de esas "metáforas rebeldes, plurales y renovadoras"?

Que el pensamiento occidental siempre ha privilegiado el alma, el raciocinio y el intelecto a expensas del cuerpo, en gran medida por identificar a este último con lo femenino, no es algo nuevo, pero sí algo a tener en cuenta para entender hasta qué punto esa secular asociación entre somatofobia y misoginia, una de las piedras angulares del 
patriarcado, se ha instalado en nuestro imaginario, en nuestras conciencias, en nuestras miradas.

Elizabeth Spelman se remonta hasta la filosofía platónica como una de las primeras teorizaciones a este respecto. Nos recuerda que en su entusiasta celebración del alma como la única fuente de conocimiento y puerta de acceso a la realidad, Platón estigmatiza el cuerpo, o parte irracional del individuo, por tratarse de un enorme obstáculo en nuestras capacidades cognitivas, al tiempo que advierte a los atenienses de los peligros de una existencia dominada por apetitos emocionales y bajos instintos. El referente inmediato de esta existencia indeseable lo constituyen las mujeres -pero también los esclavos-quienes, víctimas de las pasiones y sentidos engañosos que sus cuerpos producen, son incapaces de distinguir entre el mundo material de la apariencia y el mundo transcendente de lo eterno ${ }^{1}$. Este tipo de justificación metafísica de la misoginia es trasvasada a la doctrina cristiana a través de la patrística para seguir alimentando el pensamiento dominante en los siglos sucesivos.

Historiadores como Norbert Elias o Francis Barker han analizado el largo proceso de privatización experimentado por el cuerpo en la Edad Moderna. Un proceso asociado a esa redefinición de lo público y lo privado que tiene lugar en la Europa de los siglos XVII y XVIII, consistente en la gradual exclusión y represión de determinadas funciones corporales y que resultaría en la constitución de lo que Mijail Bakhtin llamó un "cuerpo clásico" (sin orificios ni genitales, sin apenas deseos, apetitos o anomalías) en oposición al "cuerpo grotesco". Michael Foucault los que merezcan una mayor atención por ser los que más claramente han influído a críticos y filósofos contemporáneos. En Discipline and Punish Foucault lleva a cabo un examen de todas aquellas instituciones de confinamiento -prisiones, hospitales, asilos, escuelas, conventos- que fueron fundamentales en la constitución de ese cuerpo dócil y disciplinado, base de la sociedad burguesa racionalista ${ }^{3}$. El objeto de su análisis no es otro que ese individuo controlado y supervisado por una serie de regímenes de poder, como son la religión, la ciencia o el arte, regímenes que actualmente han derivado en nuevas formas de disciplina -moda, mercado, tecnología- para adaptarse a la nueva sociedad de consumo, pero que ejercen sobre los cuerpos esa misma función normativa.

Lo que Foucault plantea respecto al cuerpo tiene además una enorme trascendencia para la definición del sujeto social, dado que podemos argumentar que el cuerpo disciplinado, discreto, bajo control, es índice de una personalidad igualmente estable y completa, autónoma y racional, que opera y se comporta dentro de los límites establecidos. Por el contrario, la transgresión de las barreras corporales, a través de la enfermedad, la incapacidad $\mathrm{y}$, en el pensamiento patriarcal, la feminidad (con su potencial para las "fisuras" en procesos como la menstruación, la lactancia o el parto), significa no sólo la

\footnotetext{
' Elizabeth V. Spelman, "Woman as Body: Ancient and Contemporary Views", Feminist Studies 8 (1) Spring (1982), pp. 109-31.

${ }^{2}$ Elias Norbert, The Civilizing Process, vol. 1: The History of Manners, Oxford, Blackwell, 1974; Francis Barker, The Tremulous Private Body: Essays on Subjection, London, Methuen, 1984.
}

${ }^{3}$ Michel Foucault, Discipline and Punish. Harmondsworth, Penguin, 1979. 
ruptura del cuerpo universal, sino la imposibilidad de acceder a la personalidad plena. En este contexto, la excesiva fisicalidad y concupiscencia tradicionalmente asignadas a las mujeres aparecen como objetivos prioritarios de estas políticas reguladoras, dado que dentro del patriarcado, el cuerpo femenino siempre ha ofrecido esa "natural" tendencia a escapar de la disciplina.

Así pues, considerando lo que parece haber sido esta historia de control y supervisión por parte de los discursos del poder, no es de extrañar que la irrupción del cuerpo grotesco, anticanónico ("abyecto" para Julia Kristeva ${ }^{4}$ ), la visibilidad de sus aspectos largamente reprimidos pueda adquirir una dimensión moral y políticamente subversiva. De hecho, el cuerpo, tradicional soporte de la identidad, se ha convertido en "campo de batallas ideológicas", como reza el famoso poster de la artista norteamericana Barbara Kruger, "Your Body is a Battleground". Esta leyenda añadida a una composición fotográfica donde se superponen el negativo y el positivo de una imagen en la que apenas es posible distinguir el rostro de un hombre o el de una mujer viene a significar precisamente ese lugar de la negociación, el conflicto y la indefinición con que el pensamiento contemporáneo quiere representar la anatomía humana y sus discursos asociados. O quizás es que "no puede" hacerlo de otra manera, lejos ya de las verdades y certezas ontológicas de otros tiempos. Desde luego, fenómenos tan característicos de la cultura postmoderna y las sociedades tecnológicas como la disolución de la identidad o el descentramiento del sujeto tienen su manifestación más visible, explícita e inmediata en el cuerpo. Y buena prueba de esa cualidad problemática son los debates éticos y la polvareda mediática surgidos en torno a cuestiones como el derecho al aborto, la eutanasia o el suicidio asistido, el uso de tejidos fetales, la ingeniería genética, la clonación, las madres de alquiler, la objeción de conciencia a los transplantes, el uso del cuerpo para la experimentación, la pornografía, el arte o la publicidad, o la mutilación por motivos religiosos, entre otras cuestiones que a nadie dejan indiferente. Y es que, frente a la lógica cartesiana que atribuye un cuerpo único, irrepetible e indivisible a un sujeto igualmente estable y bien definido, nos hallamos ahora ante un cuerpo fragmentado, desvinculado de sus significados tradicionales y vuelto a construir con todo tipo de manipulaciones tecnológicas y discursivas.

En definitiva, todo este panorama es bien indicativo de un complejo proceso de "desnaturalización" que tiene lugar en los distintos ámbitos del pensamiento contemporáneo y que, en lo que al cuerpo se refiere, se manifiesta en los distintos intentos de deconstruir esa "lógica de lo bio-lógico". Una lógica basada en estructuras binarias salud/enfermedad, entero/fragmentado, normal/anormal, mortal/inmortal, masculino/femenino, homosexual/heterosexual, uno/otro, propio/ajeno- destinadas a configurar y diseminar determinadas versiones de lo corporal a expensas de otras; $y$ en ese sentido, una lógica que se convierte en un ejercicio de poder y exclusión.

\footnotetext{
${ }^{4}$ La feminista francesa Julia Kristeva se refiere al cuerpo maternal como "abyecto", en tanto que es objeto de rechazo una vez que el sujeto se independiza del cuerpo que lo gestó, y éste comienza a representársele como el terror a la re-incorporación y a la pérdida de autonomía. Lo abyecto, al simbolizar ese miedo masculino a ser absorbido y tragado, devuelto al útero, se atribuirá no sólo al cuerpo de la madre, sino, por extensión, a toda la sexualidad femenina. Toda la iconografía de la "vagina dentata" es, por ejemplo, una clara manifestación de ese miedo de los hombres a su "oscuro objeto de deseo".
} 
Y quién mejor que las mujeres para entender lo que significa ser oprimidas y excluídas a causa de la biología. El determinismo biológico ha sustentado, por ejemplo, esa secular ecuación "naturaleza = destino", argumentando que la mujer está genéticamente predispuesta para la maternidad y que a esa función debe dedicar su existencia. No es de extrañar, pues, que uno de los primeros compromisos en la agenda del feminismo fuese desligar el componente biológico (sexo) de los significados culturales a él asociados (género). Con ello, se empezaba a cuestionar explícitamente la visión esencialista del cuerpo como algo natural e inmanente y se proponía abordarlo desde su status de construcción histórica. Dicho cuestionamiento, en tanto que ponía en el centro mismo del debate filosófico lo que hasta entonces sólo había ocupado sus márgenes (el cuerpo, y el cuerpo femenino) socavaba los fundamentos del pensamiento occidental y, en esa medida, albergaba un extraordinario potencial subversivo.

Y así al menos parece haberlo entendido una parte de la crítica feminista -bautizada por Elizabeth Grosz y Judith Allen como "body feminism"- que a partir de los años 80 se empeña, desde distintos ámbitos, en re-pensar el cuerpo femenino, aquello que, según Estrella de Diego, siempre nos ha definido pero nunca nos ha pertenecido: "Los cuerpos femeninos acaban por ser lo que la mirada del poder quiere o puede construir, quitando y poniendo según convenga, desposeyendo a las mujeres de aquello que supuestamente es lo único que han poseído, de aquello que la historia les ha dicho que es su misma esencia"s. Dado que no existe cuerpo sin mirada que lo represente y sin lenguaje que lo nombre, y que, en este caso, ambos son instrumentos de poder, será necesario desde el feminismo romper la mirada dominante e inventar un nuevo lenguaje:

"Los cuerpos femeninos son históricamente construcciones imaginarias descritas a partir de un tipo de cirugía de la representación, y por tanto literaria, que desde tiempo inmemorial ha querido construir un canon móvil que en cada momento se acomode a las sucesivas miradas del poder... Sin embargo, la misma esencia de pastiche que poseen los femeninos ha propiciado el creciente éxito del mismo en nuestra cultura bricolada: el cuerpo femenino se descubre y se exhibe como uno de los máximos representantes históricos de lo fragmentario" (de Diego: 30).

Entre las primeras mujeres en reivindicar el cuerpo para la autorepresentación se encuentran las feministas francesas -Julia Kristeva, Helène Cixous, Luce Irigaray y Monique Wittig-, quienes, partiendo de los estudios psicoanalíticos de Jacques Lacan, empezaron en la década de los 70 a proponer una inscripción literal y metafórica del cuerpo femenino en la escritura. Con la radicalidad característica de aquellos años inmediatamente posteriores al Mayo de 1968, su famosa consigna "escribir el cuerpo" -o "desde el cuerpo"tiene ese carácter de manifiesto, en tanto que anima a desmantelar el sistema falogocéntrico que siempre ha excluido lo corporal, lo maternal, lo semiótico.

Por una parte la "écriture féminine" invita a las autoras a inscribir la experiencia biográfica de su cuerpo en la literatura, una experiencia que, o bien no había tenido cabida en la literatura anteriormente, o bien se había presentado distorsionada por la óptica

\footnotetext{
${ }^{5}$ Estrella de Diego, "Ver, mirar, olvidarse, reconstruirse". 100\%., Consejería de Cultura y Medio Ambiente de la Junta de Andalucía e Instituto Andaluz de la Mujer, 29 (1993).
} 
masculina. Así, temas como la sexualidad y el placer, el parto, el embarazo, la menopausia, la menstruación, el dolor, la percepción-aceptación o rechazo-del propio cuerpo aparecen ahora explícitamente desarrollados en estos textos, en voces femeninas que casi tienen que inventar un nuevo lenguaje para contar esas experiencias sobre las que no existía una tradición escrita "en primera persona". Irigaray, por ejemplo, transforma la "diferencia" en algo positivo, celebrando precisamente aquellas características del cuerpo femenino que durante siglos han servido para la exclusión social y cultural de las mujeres: concretamente la pluralidad representada en sus múltiples formas de placer sexual o la disposición para la creación y la tolerancia plasmadas en el potencial reproductor de los vientres femeninos ${ }^{7}$. Es también en este sentido en el que se llega a equiparar la tinta de la escritura con la leche materna y la sangre menstrual -irónica respuesta a las connotaciones que el semen tiene para los escritores masculinos-: "Voz: la leche inagotable. Ha sido recobrada. La madre perdida. La eternidad: es la voz mezclada con la leche"8.

Por otra parte, la escritura del cuerpo también implica una verdadera revolución en el lenguaje, en tanto que propone abrir éste a los impulsos irracionales formulados por una especie de contradiscurso de lo semiótico, de aquello que ha sido reprimido al instaurarse el orden simbólico o la Ley del Padre, y que está asociado a los ritmos, fluidos, pulsiones y formas de representación pre-edípicas, pre-verbales, reminiscentes de ese contacto sensorial e instintivo con el cuerpo maternal ${ }^{9}$. En este contexto no es de extrañar que Cixous reivindique el mito de la Medusa -símbolo de ese miedo masculino a una sexualidad femenina oscura, desconocida e inexplorada-, pero también por extensión, las figuras de la loca, la histérica o la hechicera, representantes del desorden que, como tales, han sido históricamente desplazadas hacia la esfera de lo marginal, pero que en esta nueva filosofía poseen ese potencial privilegiado para hablar "desde fuera del discurso". En definitiva, como apunta la crítica postcolonialista Trinh T. Min-Ha, una de las carácterísticas de esta escritura es precisamente su resistencia a ser definida, catalogada:

la "escritura del cuerpo" se produce en ese lugar del exceso, entre lo abstracto y lo concreto, lo personal y lo político que las estructuras coherentes de la escritura no pueden contener. Su fisicalidad (vocalidad, tactilidad, resonancia) y marginalidad exceden la claridad racional de las estructuras comunicativas y ningún análisis convencional puede explicarlas ${ }^{10}$.

${ }^{6}$ Belén Martín Lucas, "El cuerpo femenino como emplazamiento de resistencia", Proceedings of the $20^{\text {th }}$ International AEDEAN Conference. Barcelona (1997), p. 515

${ }^{7}$ Luce Irigaray, "When Our Lips Speak Together". Feminist Theory and the Body: A Reader, Janet Price y Margrit Shildrick, eds., Edinburgh, Edinbugh University Press, 1999, pp. 82-90.

${ }^{8}$ Luce Irigaray, Yo, tú, nosotras, Madrid, Cátedra, 1992, p. 56.

${ }^{9}$ Pese a su asociación con el cuerpo femenino, este tipo de escritura no es exclusiva de las mujeres. Julia Kristeva y Hélene Cixous consideran que ciertos autores vanguardistas también supieron escribir desde el subconsciente recuperando la voz pre-simbólica que, en el caso de las mujeres, siempre se mantuvo de forma latente y paralela al lenguaje dominante. Estas carácterísticas formales incluirían la ruptura de la sintaxis y la estructura, la multiplicidad de voces y puntos de vista, o la irrupción de repeticiones y asociaciones inconscientes.

10 Trihnh T. Minh-Ha, Woman, Native, Other. Writing Postcoloniality and Feminism, Bloomington, Indiana University Press, 1989, p. 126. La traducción es mía. 
La relevancia teórica del feminismo francés en este campo es innegable, aunque a menudo ha sido acusado de querer instaurar un nuevo "body fascism", dado que el énfasis biologista de sus propuestas puede acercarnos a un nuevo esencialismo, aunque esta vez sea de signo contrario.

Sin ser ajena a esta controvertida reinvindicación de la corporealidad femenina -la dificultad de escapar a la mirada dominante y desprenderse de los significados tradicionales-, la escritora británica Jeannette Winterson es sin duda la mejor representante de esta escritura del cuerpo (literal y metafórica) en lengua inglesa. Su novela Written on the Body (Escrito en el cuerpo, 1992) gira en torno a la disección y reconstrucción del cuerpo amado desde la memoria y el deseo, cuando aquél enferma y se ausenta. Frente a la ambigüedad sexual del narrador -en todo momento se ocultan deliberadamente los marcadores genéricos-la anatomía de Louise adquiere esa preponderancia excesiva y luminosa al ser descrita por un discurso sentimental que se opone a los de la exploración y la medicina -disciplinas tradicionalmente masculinas-, invirtiendo sus tropos. Así por ejemplo, las ideas de conquista y penetración, inherentes al discurso colonial del patriarcado, son reemplazadas por las de los viajes y el conocimiento mutuo, donde las posiciones de sujeto y objeto, viajero y territorio, amante y amado, pueden intercambiarse y confundirse:

"Explórame", decías, y yo reuní mis cuerdas, cantimploras y mapas, esperando volver pronto a casa. Me he perdido en tu macizo montañoso y no encuentro la salida. A veces creo que estoy libre, que me has escupido como la ballena a Jonás, pero entonces doblo una esquina y me reconozco otra vez. Yo en tu piel, huésped de tus huesos, flotando en las cavidades que adornan las paredes de cualquier cirujano. Así es como he llegado a conocerte. Tú eres lo que conozco ${ }^{11}$.

Continuando con la metáfora geográfica, Winterson rechaza los conceptos de posesión y territorialización tan característicos del discurso dominante, proponiendo a cambio una topografía sin límites: "...voy a encontrar un mapa tan verosímil como cualquier búsqueda del tesoro. Voy a explorarte y a explotarte y tú vas a volver a dibujarme según tu voluntad. Cruzaremos mutuamente nuestras fronteras para hacer un solo país. Excávame con tus manos, porque soy buena tierra. Come de mí y déjame ser dulce." (Winterson 1998: 24-25).

En esta idea de reciprocidad algunos críticos han querido intuir el lesbianismo de Winterson, aunque en cierta medida eso sería acotar un espacio que la escritora desea dejar abierto, deliberadamente indefinido ${ }^{12}$; muy en la línea de Luce Irigaray cuando se refiere a esa sexualidad femenina plural y dispersa que puede estar en el origen de la problemática relación de la mujer con el Logos masculino: "La mujer tiene órganos sexuales por todas partes... La geografía de su placer es mucho más diversa y múltiple en sus diferencias, más sutil, más compleja de lo que pueda ser imaginada -por un sistema imaginario demasiado

\footnotetext{
${ }^{11}$ Jeanette Winterson, Escrito en el cuerpo. Barcelona, Anagrama, 1998, p. 143.

${ }^{12}$ Cath Stowers, "The Erupting Lesbian Body: Reading Written on the Body as a Lesbian Text", Postmodern Studies 25. Helena Grice \& Tim Woods, eds., Amsterdam, Rodopi, 1998, pp. 89-102.
} 
centrado siempre en lo uno y en lo mismo-""13. De hecho, el énfasis de esta novela no reside en la genitalidad, ni siquiera en las zonas erógenas convencionales; los enigmas corporales de Louise son continuamente erotizados, cualquier parte de su anatomía, por invisible o inexplorada que sea, por escasa que haya sido su presencia en la literatura amorosa: "Entre el lenguaje clínico, a través de la desapasionada visión del yo que chupa, suda, se atiborra y defeca, encontré un poema de amor para Louise. Seguiría conociéndola, y más íntimamente de lo que me permitían la piel, el pelo y la voz que ansiaba. Tendría su plasma, su bazo, su fluido sinovial. La reconocería incluso mucho tiempo después de que su cuerpo se desmoronase" (Winterson 1998: 134)

Y es que, efectivamente, Louise se desmorona, devorada por el cáncer; circunstancia que obliga al amante/narrador (o narradora) a usurpar el lenguaje científico y reemplazarlo por un discurso amoroso con el que nombrar, desde el dolor y la memoria, ese cuerpo único re-construido para la especificidad de su deseo ${ }^{14}$. De ahí que la segunda parte del libro se estructure a modo de diálogo entre dos miradas o lenguajes opuestos que pugnan por designar, y en última instancia apropiarse, del cuerpo de Louise: por una parte, el discurso de la medicina, que no hace sino crear un modelo anatómico universal donde cualquier rasgo de singularidad es anulado; y por otra, el discurso sentimental que incide precisamente en la individualidad del objeto amado.

LA ESCÁPULA U OMÓPLATO ES UN HUESO PLANO DE FORMA TRIANGULAR SITUADO EN LA PARTE POSTERIOR EXTERNA RESPECTO A LAS COSTILLAS, DE LAS QUE ESTÁ SEPARADO POR MATERIA MUSCULAR.

Cerrados como un abanico nadie sospecharía que tus omóplatos son alas. Mientras yacías sobre el vientre, modelé los afilados bordes de tu vuelo. Eres un ángel caído pero sigues siendo como son los ángeles: un cuerpo leve como una libélula, doradas y grandes alas recortadas del sol (Winterson 1998: 155)

Como puede apreciarse, a la desapasionada objetividad de la definición científica se opone el lirismo de la narración emocional, que, en su obstinada huída de la racionalidad, se adentra incluso en el terreno del realismo mágico. Y así, órgano a órgano, miembro a miembro, en una disección minuciosa y polifónica donde se cuestionan las distintas formas de representación: ¿qué versión es la real? ¿la del médico o la del amante?

${ }^{13}$ Luce Irigaray, "This sex which is not one", New French Feminisms, Elaine Marks e Isabelle de Courtivron, eds. New York, Shocken, 1981, p. 105. La traducción es mía.

${ }^{14}$ En esa enciclopedia de lo sentimental que es Fragmentos de un discurso amoroso (Madrid, Siglo XXI, 1984) Roland Barthes se refiere a este punto como uno de los fenómenos fundamentales de la transferencia romántica: el hecho de que nó solo el sujeto construye al objeto amoroso sino que además, a lo largo de este proceso el sujeto mismo es construido por el objeto de su deseo:

Encuentro en mi vida millones de cuerpos; de esos millones puedo desear centenares; pero, de esos centenares, no amo sino uno. El otro del que estoy enamorado me designa la especificidad de mi deseo. Esta elección, tan rigurosa que no retiene más que lo Único, constituye, digamos, la diferencia entre la transferencia analítica y la transferencia amorosa: una es universal, la otra específica. Han sido necesarias muchas casualidades, muchas coincidencias sorprendentes ( $\mathrm{y}$ tal vez muchas búsquedas, para que encuentre, entre mil, la Imagen que conviene a mi deseo (Barthes 1984: 27-28) 
No puedo pensar en la doble curva, tan ágil y fluida en sus movimientos, como en una cordillera ósea. Pienso en ella como en el instrumento musical que tiene la misma raiz. Clave. Tecla. Clavicordio. El primer instrumento de cuerda con teclado. Tu clavícula es a la vez teclado y clave. Si toco con los dedos las hondonadas que hay detrás del hueso me pareces un cangrejo de cáscara blanda. Busco los huecos entre los ligamentos de los músculos para apretarme contra los acordes de los tendones de tu cuello (Winterson 1998: 153)

Es evidente que el amante/narrador (o narradora) se resiste a las estrategias de homogeneización de los discursos dominantes, no sólo el de la medicina, sino también el del amor romántico convencional: "El problema son los clichés. Una emoción concreta necesita una expresión concreta. Si lo que siento no es concreto ¿debo llamarlo amor?...El hundido sillón de clichés. No pasa nada, miles de culos se han sentado en él antes que yo. Los muelles han cedido, la tela huele y resulta familiar "( Winterson 1998: 13) En su intento de encontrar un lenguaje que escape de los estereotipos, esta voz narradora pone en evidencia toda esa tradición sentimental que también ha privilegiado una determinada versión idealizada y puritana de lo corporal (el cuerpo "clásico" del que habla Bakhtin). Como alternativa, la novela acentúa la fisicalidad más descarnada, rompiendo la jerarquía de la representación -esa que siempre ha dictado lo que debe ser visible o invisible, nombrable o innombrable-, y poniendo en un primer plano aquellos aspectos del cuerpo que, por obscenos y escatológicos, han sido sublimados y ocultados por el discurso dominante. El cuerpo amado es aquí ese organismo ("grotesco" en la terminología bakhtiniana) que suda, defeca, huele, orina, menstrúa, y enferma. Es como si, observado con una lente de aumento, se le sometiera a una perspectiva extraña, nada frecuente, desvelando recovecos hasta ahora inaccesibles. El resultado es un ejercicio de descontextualización, en la medida en que, desde el "extrañamiento", se nos impide reconocer lo que nos es conocido, familiar, "natural"15.

Es evidente que en las entrañas de Louise no sólo se libra la batalla contra la enfermedad:

En los rincones secretos de su timo, Louise se está esforzando demasiado. Su leal biología depende de la regulación, pero los linfocitos se han convertido en criminales. No obedecen las normas. Están plagando la corriente sanguínea, alterando el tranquilo orden del bazo y el intestino. Se hinchan con orgullo en los ganglios linfáticos. Su tarea solía ser mantener al cuerpo a salvo de los enemigos externos. Eran su inmunidad, su defensa contra la infección. Ahora son los enemigos infiltrados. Las fuerzas de seguridad se han rebelado. Louise es víctima de un golpe de estado (Winterson 1998: 137)

\footnotetext{
${ }^{15}$ Una estrategia "desfamiliarizadora" parecida es la empleada por el artista norteamericano Robert Mapplethorpe cuando fotografía distintas partes de la anatomía de sus modelos en unos primeros planos muy cercanos. Al carecer del contexto -una zona del cuerpo con la que referenciar ese plano--el espectador apenas puede reconocer si se trata de un ombligo, un pezón o cualquier otro miembro. Paradójicamente la excesiva "cercanía" de la lente respecto a su objeto tiene como efecto un "distanciamiento" del espectador respecto a dicho objeto.
} 
Todo su cuerpo se constituye, además, en lugar de negociación de los distintos discursos -científicos, literarios, psicológicos, emocionales-que luchan por hacerse con las definiciones, con el poder de los significados. $\mathrm{Y}$ es precisamente en torno a esta idea de complejidad discursiva donde Winterson recupera esa otra equiparación entre cuerpo y texto. Una identificación que tampoco es nueva (ya en la Biblia se nos dice cómo "el Verbo se hace carne"), pero que aquí puede leerse a la luz del postestructuralismo, al sugerirse que no sólo se trata de un texto, sino un texto hecho a partir de otros textos:

Escrito en el cuerpo hay un código secreto, sólo visible bajo ciertas luces; los posos de toda una vida se acumulan en él. En algunos sitios, el palimsesto está tan trabajado que las letras, al tacto, parecen braille. Me gusta guardar mi cuerpo enrollado, lejos de las miradas curiosas. Sin llegar nunca a desplegarme demasiado, a contar toda la historia. No sabía que las manos de Louise podían leer. Ella me ha traducido, convirtiéndome en su propio libro (Winterson 1998: 108)

Aquí se añade una vez más ese concepto de reversibilidad, es decir, el hecho de que el sujeto lea al cuerpo amado como texto, pero que también en el acto de leer/mirar/amar/desear él mismo sea construido como texto. Frente a la retórica patriarcal que tradicionalmente ha considerado al cuerpo femenino como territorio expuesto a la penetración y a la posesión, como "página en blanco" sobre la que escribir con la pluma fálica (recordemos el juego de palabras sugerido por las feministas americanas "pen=penis"), aquí el Yo narrativo se ofrece simultáneamente para leer y para ser leído. En última instancia, Winterson parodia los paradigmas masculinos del explorador, el médico y el autor, proponiendo a cambio la reciprocidad del deseo y de la textualidad. En la medida en que el Yo se reconoce en el cuerpo de su Otro, ya no es sólo "creador" sino "creado": "Las huellas de tus manos están por todo mi cuerpo. Tu carne es mi carne. Me has descifrado y ahora soy como un libro abierto. El mensaje es muy sencillo: mi amor por ti." (Winterson 1998: 128)

Escrito en el cuerpo no es la única novela en la que Winterson plantea una política corporal alternativa. En menor medida Sexing the Cherry (1989) y Art and Lies (1995) se hacen eco de los debates surgidos en torno a estos discursos, al presentar personajes con una anatomía anormal, y por tanto transgresora. Art and Lies se ubica en el mundo sexualmente ambiguo de la ópera, donde uno de sus protagonistas, Hendel, es un castrato y otro, Saphho, una hermafrodita, ilustrando ambos no sólo la inestabilidad de los roles genéricos, sino incluso de la genitalidad que supuestamente los ha justificado y perpetuado. Sexing the Cherry es una novela de aventuras ambientada en la convulsa Inglaterra del siglo XVII. Aquí la transgresión de lo corporal tiene además connotaciones políticas si se tiene en cuenta que la Guerra Civil supuso la desmembración del "cuerpo" del Estado al desposeerlo de su cabeza -el rey Carlos I, que fue decapitado en 1649-. No faltan en la novela alusiones a las numerosas decapitaciones, mutilaciones, descuartizamientos públicos, y en general a toda esa espectacularización de lo somático -tan característica del gusto barroco por lo "gore"- que, con el paso a la modernidad burguesa fue quedando relegado al terreno de lo privado. Sexing the Cherry también representa esta transgresión de la armonía física y estética en la figura gigantesca de su narradora -"the Dog-woman"- , con 
una horrible anatomía que excede todas las limitaciones de peso y volumen, una desviación que la sitúa en el ámbito de lo grotesco ${ }^{16}$.

La mujer con una anatomía "anormal" es un motivo recurrente en la narrativa anglófona contemporánea con el que se quiere significar esa reivindicación que las mujeres vienen haciendo de su propio cuerpo en las últimas décadas. Una vez deja de ser el tradicional locus de la feminidad, este cuerpo que se sale de los cánones dominantes se convierte en emplazamiento de la resistencia ${ }^{17}$. Esta irrupción de "lo monstruoso femenino" supone una llamada de atención sobre la fisicalidad (en su dimensión más desagradable y anticanónica), y además pretende hacer visible lo que siempre se ha querido invisibilizar bajo la uniformante mirada del poder.

Éste parece ser el planteamiento central en The Life and Loves of a She-Devil (1983) de Fay Weldon, una de esas autoras que han bebido de la teoría feminista pero también de la conciencia irónica del postmodernismo. En esa medida, la novela incorpora temas tan tradicionalmente asociados a la feminidad como puedan ser el discurso romántico, los valores familiares, la novela rosa, o la cirugía estética, pero que aquí son abordados desde el distanciamiento más paródico ${ }^{18}$. La protagonista de esta historia es Ruth Patchett, una mujer fea, torpe y vulnerable, que, abandonada por su marido, se aventura en la diabólica destrucción de todos aquellos responsables de su sufrimiento. Para llevar a cabo su venganza es imprescindible una transformación radical que comienza justamente en el cuerpo, el lugar donde se origina el poder -o la ausencia de poder, en su caso-. Y es que la anatomía de Ruth como soporte de la transgresión, como distintivo de la "diferencia", se constituye en "bofetada estética", sobre todo si lo observamos en clara oposición a los standards de feminidad romántica representados por Mary Fisher, la amante de su marido:

Mido 1'90 m, lo cual está bien para un hombre pero no para una mujer. Soy tan morena como Mary Fisher es rubia, y tengo una de esas mandíbulas prominentes que las mujeres altas y morenas suelen tener, y ojos demasiado hundidos en mi cara, y una nariz aguileña. Mis hombros son anchos y huesudos y mis caderas anchas y carnosas, y los músculos de mis

\footnotetext{
${ }^{16} \mathrm{La}$ imagen de su inmensa vagina como una profunda gruta que se traga a uno de sus amantes en pleno acto sexual remite de inmediato al sentido etimológico de lo "grotesco", término acuñado para describir aquellas formas caprichosas y divergentes que aparecieron en las cuevas de Tito en Roma, y que desde entonces sirvió para designar todas las manifestaciones artísticas que se alejaban del canon clásico establecido. (Sánchez-Palencia e Hidalgo, 1996: 548). La escena es, además, una clara reapropiación paródica del mito masculino de la "vagina dentata".

${ }^{17}$ Esta idea de resistencia supone la oposición al patriarcado, pero también a otras formas de poder, como puede ser el Imperio. A este respecto Martín Lucas analiza dos ejemplos de narrativas feministas postcoloniales -The Biggest Modern Woman of the World (1983) de la canadiense Susan Swan y Lilian's Story (1985) de la australiana Kate Grenville- donde la anatomía excéntrica y anticanónica de las protagonistas desafía explícitamente la ortodoxia de la feminidad victoriana y el discurso colonial a ella asociado.

${ }^{18}$ Para un análisis de esta novela como re-escritura del género romántico, véase Carolina Sánchez-Palencia Carazo, El discurso femenino de la novela rosa en lengua inglesa, Publicaciones de la Universidad de Cádiz, 1997, pp. 224-234.
} 
piernas están bien desarrollados. Mis brazos, lo juro, demasiado cortos para mi cuerpo. Mi naturaleza y mi apariencia no concuerdan ${ }^{19}$.

Jugando con la fetichización que experimenta la imagen femenina en la cultura popular -donde efectivamente siempre es reificada, dividida y fragmentada por y para satisfacer la mirada masculina ${ }^{20}$-, Weldon nos muestra aquí una anatomía deforme y desmesurada, que excluye a Ruth del afecto familiar -"Pobre patito feo', me dijo mi madre una vez...Me habría amado si pudiese. Pero las cosas feas y disonantes le producían asco"-, y, sin duda, del mercado sentimental:

"En las novelas de Mary Fisher, que se venden por cientos de miles con sus portadas rosa brillante y doradas, las heroínas menudas y bien proporcionadas levantan sus ojos húmedos hacia hombres apuestos, y abandonándolos, los ganan para sí. Las mujeres menudas pueden levantar sus ojos hacia los hombres. Pero las mujeres de 1'90 m. tienen problemas para hacerlo". (Weldon 1993: 29)

Además de la burla de esa delicada feminidad, esta reapropiación del discurso amoroso de las novelas rosa es claramente perversa, porque lejos de reflejar sus convenciones y estética, las refracta, proyectando sobre ellas una mirada distinta y descreída.

En una clara inversión del pacto faústico -que tampoco debe pasarnos desapercibida por cuanto supone de re-utilización paródica de un mito masculino ${ }^{21}$-, esta diablesa se propone su particular "asalto al poder" transformando a los distintos hombres con los que se va relacionando, todos ellos representantes de los discursos patriarcales y responsables, por tanto, de la marginación de Ruth. Así, primero el marido y sucesivamente el juez, el sacerdote y los cirujanos se convierten en víctimas propiciatorias de su diabólico proyecto, en una significativa usurpación femenina de la autoridad conyugal, jurídica, religiosa y científica.

${ }^{19}$ Fay Weldon, The Life and Loves of a She-Devil, London, Sceptre, 1993, p. 11. Las traducciones de esta edición son mías.

${ }^{20}$ Desde hace años buena parte de la crítica feminista concentra sus esfuerzos en denunciar ese tipo de tratamiento de las imágenes femeninas en la publicidad, por considerar que, incluso en los mensajes no supuestamente pornográficos, a menudo transmiten un ideal de mujer siempre dispuesta a satisfacer el deseo y las fantasías masculinas; un ideal -de belleza, juventud, delgadez, disponibilidad, etc - que ha sido interiorizado por las mismas mujeres, lo que demuestra hasta qué punto no sólo nuestros cuerpos, sino también nuestras mentes, han sido colonizadas por la mirada masculina, en un fenómeno de voyeurismo generalizado. Un argumento similar es el utilizado por Laura Mulvey en su famoso análisis del cine clásico "Visual Pleasure and Narrative Cinema", un ámbito que, en su opinión, está de tal manera articulado por y para la mirada masculina que a la espectadora femenina sólo le está permitida una identificación con esa mirada dominante. Para desafiar esa identificación con lo masculino la espectadora tendrá que romper necesariamente con el principio de placer que construye, explota y manipula las representaciones cinematográficas de la mujer.

${ }^{21}$ Conviene señalar que el pacto faústico no se produce aquí en términos de una alianza con el diablo -porque, después de todo, eso sería rendirse a un poder milenario y patriarcal-, sino de la propia transformación de Ruth en diablesa: "Rió y dijo que se estaba rebelando contra Dios. Lucifer lo había intentado y había fallado, pero él era varón. Ella pensó que podía hacerlo mejor, siendo mujer". La secular "demonización" de la mujer y de su anatomía -tener un "cuerpo para el pecado"- se toma aquí en su sentido más literal y se lleva hasta sus últimas consecuencias. 
Sin embargo la fase final de esta venganza tiene un status de sacrificio autoimpuesto en tanto en cuanto lleva a la protagonista a mutilarse y reconstruir su horrenda apariencia para adecuarla a los cánones de belleza dominantes, hasta el punto de convertirse en un exhuberante objeto de deseo para esos modernos Pigmaliones que participan en su metamorfosis.

Obviamente este cierre narrativo puede despertar reacciones controvertidas si la dolorosa transformación de Ruth se entiende únicamente como sumisión a la estética patriarcal y a la tiranía que ésta ejerce sobre los cuerpos femeninos. Pero no ver más allá del bisturí como "solución final" supone, efectivamente, contribuir al malentendido que muchas mujeres que se sirven del cuerpo -en el arte o la literatura- para hablar de su propio cuerpo tienen que combatir. Un malentendido propiciado por la dificultad para traspasar esa mirada dominante que históricamente ha definido y significado los cuerpos femeninos. Fay Weldon es una de esas artistas cuyas propuestas pueden resultar desconcertantes y hasta "políticamente incorrectas", pero desde luego, no carentes de toda una consciente y compleja reflexión de fondo. En la novela la cirugía es obscenamente real, pero también tiene un componente simbólico, al desvelar los traumáticos procesos de fragmentación a los que las mujeres se someten para gratificar la mirada y el deseo masculinos:

Cuando sus ojos se curaron, rompieron sus pómulos y se los alisaron: y cuando los hematomas fueron remitiendo le recortaron y alteraron la silueta de la mandíbula. Tomaron piel lisa de sus nalgas y la graparon a los contornos de su rostro, en la línea donde nace el cabello, para dejarle una frente suave y despejada. Le estiraron la piel de la papada, la elevaron hasta las mejillas y la remetieron. Rellenaron con silicona las arrugas alrededor de la boca y la nariz y trataron los capilares rotos con inyecciones de láser. Borraron los lunares y el vello facial y aprovecharon para levantar las comisuras de su boca para dejarle esa expresión de agradable esperanza. Nuevos dientes le fueron implantados, uno a uno, usando un método tan tedioso y doloroso que apenas se empleaba...Toda la cara era un amasijo de moratones y sus ojos yacían en el fondo de unos agujeros oscuros, pero ya se veía que estaba extraordinariamente hermosa. (Weldon 1993: 231-232)

Un pasaje así casi nos obliga a mirar hacia otra parte con desagrado, pero en definitiva lo que Weldon nos está mostrando a través de su broma macabra es la imagen más cruda y explícita de un fenómeno cada vez más frecuente en las sociedades capitalistas contemporáneas que se llaman civilizadas. A este respecto resulta muy interesante la denuncia de Naomi Wolf al modelo feroz - por inalcanzable-que plantea la industria de la moda obligando a las mujeres a regímenes perniciosos, desórdenes alimenticios, peligrosísimas operaciones de cirugía estética, así como ritos iniciáticos enormemente traumáticos; en definitiva un modelo tiránico, sustentado por prácticas disciplinarias basadas en criterios de exclusión, carencia e inadecuación ${ }^{22}$.

El énfasis que esta novela pone en la desmembración -después de operarse el rostro Ruth se acorta los brazos y las piernas, se reduce el pecho, los muslos, las nalgas, la cintura y el abdomen- supone en realidad toda una meditación sobre la artificialidad del cuerpo femenino y el carácter normativo de los discursos que lo definen. La desarticulación de ese

\footnotetext{
${ }^{22}$ Naomi Wolf, El mito de la belleza, Barcelona, Emecé, 1991.
} 
tradicional soporte de la feminidad supone, por tanto, -aunque el precio sea la automutilación- el cuestionamiento de toda esa identidad femenina que se origina y se perpetúa allí mismo: siempre se nos ha dicho que "las mujeres somos esencialmente cuerpo".

Las semejanzas de esta novela con la obra de Orlan son demasiado evidentes como para pasar desapercibidas. La performer francesa se sometió durante años a sucesivas operaciones de cirugía estética para hacer realidad el sueño de la mujer más hermosa, aquella que está compuesta por las partes más bellas de las mujeres más hermosas que jamás han existido. Así, en esta especie de homenaje suicida a la historia del arte ha ido reconstruyendo, fragmento a fragmento, sobre su propio cuerpo, el canon estético femenino: la frente de la Gioconda, los ojos de la Psique de Geròme, la nariz de Diana de la Escuela de Fontainebleau, la boca de la Europa de Boucher y la barbilla de la Venus de Botticelli. Traducir en cicatrices y costurones este feminismo transgresor y perverso, supone, aún a riesgo de ser malinterpretado, "llevar la burla ancestral de la cirujía de la representación hasta el quirófano, actuando físicamente sobre su cuerpo y mostrando el proceso de adecuación al canon como el horror de la disección: cortar y recoser." (de Diego, 35). Orlan ha recogido el planteamiento subyacente a lo que ella misma ha denominado su "arte carnal" en un controvertido manifiesto que también puede servirnos para interpretar la narrativa de Fay Weldon a la luz de este debate sobre la re-conquista feminista del cuerpo. En su opinión, el arte carnal es un autorretrato en el sentido clásico, aunque realizado con la tecnología contemporánea. Ubicado entre la figuración y la desfiguración, es una inscripción en la carne, en la medida en que nuestro tiempo lo permite. Lejos de constituir el ideal inamovible que antaño representaba, el cuerpo se ha convertido en algo "modificado y recién hecho". Desde el fondo de estos montajes truculentos, la artista francesa insiste en la importancia del pastiche y el collage como estrategias necesarias para deconstruir toda una tradición estética que ha delimitado extremadamente las diferencias y las fronteras entre géneros. En este punto se inscribe en una dinámica creadora que Bakhtin denominó "carnavalesca" en cuanto que rompedora de convenciones y aglutinadora de voces y formas diversas, y que más recientemente el postmodernismo ha reivindicado en su celebración de la polifonía y la heterogeneidad.

Es en este contexto en el que podemos situar a Angela Carter, la última de las autoras que ocupan este artículo, porque su obra ejemplifica perfectamente esa irreverente reescritura de la tradición literaria desde una perspectiva feminista. The Bloody Chamber ( $L a$ cámara sangrienta 1979), una colección de relatos cuyo título hace referencia a la historia de Barbazul, constituye una revisión perturbadora de los cuentos de hadas en tanto que transmisores de un imaginario femenino definido por la pasividad y la vulnerabilidad. La lógica simplista y maniquea de los relatos tradicionales es reemplazada por toda una serie de meditaciones surrealistas en torno a las fantasías infantiles, especialmente en lo que se refiere a la ambigüedad del deseo. De hecho, en estas historias el cuerpo femenino adquiere una sensualidad barroca y exhuberante no carente de connotaciones eróticas. Pero se trata de un erotismo siempre asociado a la muerte, la violencia y el dolor físico. La protagonista de "The Bloody Chamber", por ejemplo, describe el regalo de bodas de su marido, ese maníaco coleccionista de esposas, como "un estrangulador de rubíes, de dos pulgadas de 
ancho, semejante a una preciosa incisión en la garganta" ${ }^{23}$. Es precisamente en esa complacencia femenina en la mirada masculina -por amenazadora que resulte- donde radica lo incómodo y perturbador de la propuesta de Angela Carter, siempre fascinada por los complejos entresijos del deseo sexual, en tanto que éste a menudo entra en conflicto con nuestra ideología de lo "políticamente correcto". En ese sentido, y frente al famoso retrato de Moreau Sacrificial Victim como correlato premonitorio, esta misma protagonista no puede sino reconocerse irresistiblemente atraída -y al mismo tiempo aterrada- por ese marido enigmático y perverso, a cuya mirada se expone como la modelo del cuadro lo hizo a su pintor:

¿Conocía yo la historia de cómo aquel cuadro fue pintado? ¿Cómo, cuando ella se desnudó para él por primera vez, se vistió con ese involuntario sonrojo que tiñó sus mejillas, sus pechos, sus hombros, sus brazos, todo su cuerpo?...No. No tenía miedo de él, sino de mí misma. Parecía que había vuelto a nacer en sus ojos inexpresivos, nacida bajo una forma desconocida, nada familiar. Apenas podía reconocerme en sus descripciones, y sin embargo, ¿no habría algo de esa certeza bestial en ellas? Y, a la luz del fuego, me sonrojé de nuevo, imperceptiblemente, al pensar que él podría haberme elegido, porque en mi inocencia, habría podido notar un especial talento para la corrupción. (Carter 1998: 20)

Todo el pasaje se centra en ese juego irónico, pero al mismo tiempo perturbador, en torno a la idea de la mirada masculina (esa que siempre fragmentó la anatomía femenina para recrearla a su antojo y así poder poseerla); un juego donde no existen blancos y negros, sino precisamente toda una gama de grises que deja entrever esas zonas indefinidas y confusas -entre la atracción y el temor, entre la inocencia y la corrupción, entre el bien y el mal, entre la sumisión voluntaria y la posesión- que los relatos convencionales simplemente excluyen de su retórica inequívoca.

Desde esa crítica a la imagen de pasividad y debilidad femeninas que el folklore tradicional nos ha transmitido, Carter nos presenta heroínas con iniciativa, recursos y voluntad propia -a pesar de la autoridad sádica e ineludible de los padres y esposos-, que a menudo invierten esa mirada dominante, siendo la óptica femenina la que se impone sobre el hombre como su objeto de deseo. Ese es el caso de la abuelita en "The Company of Wolves", que parece celebrar con un masoquismo ambivalente la agresión del lobo:

Se quita la camisa. Su piel es del color y la textura del vello. Una erizada franja de pelo recorre su vientre, sus pezones están maduros y oscuros como una fruta envenenada, pero está tan delgado que, se le podrían contar las costillas bajo su piel, si él te diera tiempo para hacerlo. Se quita los pantalones y ella puede ver lo velludas que son sus piernas. Sus genitales, enormes. Ah! enormes. Lo último que la anciana vio en este mundo fue a un hombre joven, de ojos como brasas, desnudo como una roca, acercarse a su cama. (Carter 1999: 116)

Es evidente que los relatos nos ofrecen una sexualidad explícita y animal, con un énfasis en la genitalidad, y en absoluto sublimada o camuflada con el lenguaje sentimental.

23 Angela Carter, The Bloody Chamber and Other Stories, Harmondsworth, Penguin, 1999, p. 11. Las traducciones de esta edición son mías. 
A lo largo de estos cuentos de hadas "re-visitados" puede verse cómo Carter traslada esta estética perturbadora al ámbito del cuerpo, haciendo de éste escenario de la confusión. En casi todos los relatos el motivo tradicional de la metamorfosis, vuelve a utilizarse para imaginar una posición de la mujer que, en última instancia, cuestione los binarismos en que el pensamiento dominante se sustenta: humano/animal, mortal/inmortal, todo/fragmento, masculino/femenino. Toda la serie basada en el cuento de Caperucita Roja -"The Werewolf", "The Company of Wolves" y "Wolf-Alice"- explora la transformación de humanos en lobos y de lobos en humanos; incluso, si nos fijamos en ese énfasis morboso en la mutilación, podría hablarse de sustitución de partes humanas por partes animales. De manera similar, los dos relatos inspirados por La Bella y la Bestia -"The Courtship of Mr. Lyon" y "The Tiger's Bride"- apuntan hacia ese colapso de identidades y emociones que, en la unión final, se tornan sexualmente ambiguas y perversas. En "The Snow Child" la protagonista sin nombre y sin voz se funde con la nieve una vez que el deseo necrofílico e incestuoso de su padre ha sido consumado:

Sollozando, el conde bajó de su caballo, se desabrochó los pantalones y clavó su miembro viril en la niña muerta...Entonces la muchacha empezó a derretirse. Pronto no quedó nada de ella, solamente una pluma que cualquier pájaro podría haber dejado caer; una mancha de sangre, como la huella de un zorro cazado sobre la nieve; y la rosa que había arrancado del arbusto (Carter 1999: 92)

Las frecuentes alusiones a la sangre femenina pueden interpretarse como alegorías de la menstruación y madurez sexual, que, en el caso de "The Snow Child", es un proceso cargado de fatalismo, pero que en otros casos, como en el de la moderna Caperucita, es indicio de su emancipación:

Sus pechos ya han empezado a hincharse; su cabello es como algodón, tan claro que apenas dibuja una sombra sobre su pálida frente; sus mejillas son de un emblemático rojo y blanco, y acaba de empezar a sangrar como una mujer, el reloj dentro de ella que sonará, de aquí en adelante, una vez al mes.

Se yergue y se mueve sobre el invisible pentáculo de su propia virginidad. Es un huevo sin romper; una vasija sellada; tiene dentro de sí un espacio mágico cuya entrada está taponada por una membrana; es un sistema cerrado; no sabe cómo temblar. Posee un cuchillo y no le teme a nada (Carter 1999: 113-14)

La sangre es un tema central en "The Lady of the House of Love", el único cuento de la colección que versa sobre un vampiro, o más concretamente una vampiresa, en lo que es sólo la primera de las muchas inversiones genéricas sobre las que se estructura el relato: se trata de una Nosferatu que exige la sangre de hombres vírgenes, y sin embargo será el chico que chupe de su dedo quien se convierta en vampiro, transformándose ella en humana y recuperando así, la temporalidad, es decir, en su caso, la muerte. Es precisamente en este personaje donde más claramente Carter reivindica el concepto de lo grotesco como nuevo paradigma de belleza: "Es tan hermosa que resulta anti-natural; su belleza es una anomalía, una deformidad, porque ninguno de sus rasgos exhibe alguna de esas imperfecciones conmovedoras que nos reconcilian con la imperfección de la condición humana. Su belleza es un síntoma de su desorden, de su desalmada naturaleza". (Carter 1999: 94). Y de hecho, esa retórica de la negatividad -"anti-natural", "anomalía", "deformidad", "imperfección", 
"desorden", "desalmada"- la sitúa en el ámbito de la subversión no sólo estética, sino también moral.

Pero no son éstas las únicas criaturas híbridas y monstruosas que habitan el universo narrativo de Angela Carter, una de las autoras contemporáneas que más claramente ha decidido distorsionar la "realidad" para así desvelar el status de construcción de todo aquello que se nos ha impuesto como "real" y "natural". La opción del realismo mágico, le permite, por ejemplo, incluir en Night at the Circus (1984),toda una galería de "freaks" que va desde una mujer pájaro hasta un grupo de monos que negocian su contrato con el director del circo. Mientras que en The Passion of the New Eve (1977) podemos encontrar a una gigantesca diosa negra con genitales híbridos, producto de la más avanzada cirugía y máximo exponente de la fertilidad ${ }^{24}$.

En su práctica re-visionista Carter también sugiere una hibridación desde el punto de vista literario. Para ella, la anarquía de las formas no sólo afecta al cuerpo anatómico sino al "corpus" de la literatura, en esa analogía entre lo carnal y lo textual que, como ya se ha apuntado, puede rastrearse hasta la Biblia. De alguna manera puede decirse que la contaminación de distintos modos y conceptos de escritura -culto/popular, crítica/ficción, original/copia, real/fantástico, historia/ficción- tan característica de la creación postmodernista genera "monstruos" literarios que transgreden la ortodoxia excluyente del canon.

Habiendo analizado estos ejemplos de narrativas contemporáneas, así como algunos de los paradigmas teóricos que las inspiran, podemos afirmar que la crítica feminista y sus planteamientos en torno a una política del cuerpo han contribuído a repensar el cuerpo femenino, pero también el concepto mismo de cuerpo como tradicional emplazamiento de la identidad, como soporte de un sujeto único, estable y monológico. Frente a la idea esencialista de identidad, con sus significados estables e inamovibles, Judith Butler, por ejemplo, propone el paradigma constructivista de lo provisional y lo performativo ${ }^{25}$. Y es evidente que este cambio conceptual tiene en el cuerpo su escenario más explícito y visible, en tanto que éste deja de ser el lugar donde se realiza la identidad (genérica, racial, sexual, nacional, etc) para convertirse en encrucijada de discursos y tecnologías. Porque no es sólo en el marco teórico del postmodernismo donde se cuestionan las tradicionales certezas ontológicas asociadas al sujeto (y a su soporte más inmediato, el cuerpo), sino que es

\footnotetext{
${ }^{24}$ Jeanette Winterson y Angela Carter parecen sumarse a toda una tradición literaria femenina en torno a la representación de estas criaturas híbridas, metamorfoseadas, fragmentadas y bricoladas, que perfectamente puede entenderse como rechazo a la idea del sujeto cartesiano tan característico del pensamiento patriarcal. Una tradición que empezaría en el Frankenstein de Mary Shelley, pasando por Orlando de Virginia Woolf y más recientemente la ciencia ficción de Joanna Russ (The Clonning of Joanna May) o las utopías faústicas de Emma Tennant (Faustine y The Strange Case of Mrs. Jeckyll and Ms. Hyde), entre otros ejemplos.
}

25 Udith Butler explica el género sexual como resultado de la repetición -a modo de representación o performance- de determinadas prácticas que, como los actos de habla, se cargan de significado en un determinado contexto. Esta teoría sustituye la idea de sujeto (sexuado, en este caso) como "origen y esencia" por la de "efecto" de dicha repetición. Así el sujeto no "es", sino que "se convierte en" (imita, cita, se apropia, pone en escena la condición de) masculino, femenino, homosexual, heterosexual, etc. Gender Trouble: Feminism and the Subversion of Identity, New York, Routledge, 1990. 
también el peso de las nuevas tecnologías, como puedan ser la cirugía, la ingeniería genética o la robótica- lo que nos obliga a reconsiderar el cuerpo y sus límites tradicionales.

En esta llamada de atención sobre las nuevas anatomías hay que destacar el trabajo de Donna Haraway para quien el ciborg (ese ser híbrido mitad organismo mitad máquina) representa nuestra postmoderna "naturaleza" y, paradójicamente, se ha convertido en la definición misma de lo humano. A la vista de cómo las nuevas tecnologías biológicas y telemáticas han re-dibujado nuestros cuerpos y nuestras ideas sobre los mismos, su controvertido "Manifiesto Ciborg" plantea un modelo que tenga en cuenta las ambigüedades y la desaparición de las categorías binarias, esas que siempre han privilegiado un término a expensas del otro. Los más recientes avances tecnológicos transgreden las fronteras entre lo mortal y lo inmortal, lo natural y lo artificial, lo real y lo virtual, y en esa medida no hacen sino confirmar, desde el ámbito de la ciencia lo que ya se auguraba desde el terreno de la filosofía y la crítica cultural: el carácter provisional del sujeto y de sus categorías epistemológicas.

Pero más allá de su crítica al pensamiento totalizador y excluyente, lo que el ciberfeminismo de Haraway tiene de innovador es su actitud tecnofílica, dentro de una tradición feminista que, reivindicando la Naturaleza, siempre ha demonizado la tecnología como la más poderosa aliada del patriarcado:

Pero ya no existe ni la naturaleza ni el cuerpo, dice Haraway, al menos ya no en el sentido que tuvieron en el Siglo de las Luces; ambos están contaminados filosóficamente de manera definitiva, a partir del momento en que algunos bebés tienen corazón de mono, y ciertos ratones, genes humanos. La tecnología de este fin de siglo, de acuerdo con filosofias como el postestructuralismo -que considera que la naturaleza, el cuerpo y demás nociones fundamentales son constructos culturales--, ha vuelto caducas no solamente las justificaciones del patriarcado, sino todo tipo de reivindicación de una identidad orgánica o natural. En otras palabras, no solamente es "dios" quien ha muerto, sino también la "diosa" 26.

$\mathrm{Y}$ es que efectivamente, frente a las ideas de totalización y dominio inherentes a la categoría "diosa", la imaginería del ciborg -con quien las mujeres estamos llamadas a identificarnos aunque sólo fuese por esa familiaridad histórica con lo fragmentario y lo bricolado, con la inestabilidad y la indefinición- ofrece una alternativa al dogma de los dualismos que explicaban nuestras fisiologías y nuestras posibilidades de existencia. 
